\title{
Specific primers for the detection of the black-yeast fungus associated with lethargic crab disease (LCD)
}

\author{
Marcio R. Pie ${ }^{1,2}$, Walter A. Boeger ${ }^{1,2, *}$, Luciana Patella ${ }^{1,2}$, Vânia A. Vicente ${ }^{2,3}$, \\ Raphael O. Ribeiro ${ }^{1,2}$, Antonio Ostrensky ${ }^{2,4}$
}

${ }^{1}$ Departamento de Zoologia, ${ }^{2}$ Grupo Integrado de Aqüicultura e Estudos Ambientais, ${ }^{3}$ Departamento de Patologia Básica, and ${ }^{4}$ Departamento de Zootecnia, Universidade Federal do Paraná, Curitiba, Paraná, Brazil

\begin{abstract}
Lethargic crab disease (LCD) is an emerging infirmity that has been causing extensive mortalities in populations of the mangrove land crab Ucides cordatus (Ocypodidae) along the Atlantic coast of Brazil. Previous studies have indicated that LCD is associated with a dematiaceous fungus, Exophiala cancerae de Hoog et al. In the present study, we sequenced the internal transcribed spacer (ITS) of the rDNA region of this black yeast species and developed species-specific PCR primers. Sensitivity tests indicated that the developed protocol is capable of detecting very small amounts of target DNA. Also, the application of the protocol to a variety of other dematiaceous fungi did not generate any false positives. The specific primers provided in the present study represent an important tool for rapidly surveying a large number of crab individuals, as well as environmental samples. Such knowledge will be instrumental in understanding the epidemiological dynamics of LCD.
\end{abstract}

KEY WORDS: Lethargic crab disease $\cdot$ Diagnosis $\cdot$ Exophiala cancerae

Lethargic crab disease (LCD) has been responsible for repeated outbreaks that have severely depressed local populations of the mangrove land crab Ucides cordatus (Decapoda: Ocypodidae) along the Brazilian coast since it was first reported in 1997 (Boeger et al. 2005). The main symptom of LCD is an increasingly weak motor control, particularly of pereiopods and chelae, causing lethargy and poor balance, followed by death of the sick individual. Fisheries of the mangrove land crab have been heavily affected by LCD outbreaks. Some mangroves in the states of Paraíba and Bahia have experienced reductions in the fishing yields of 84 and $97.6 \%$, respectively (Nóbrega \& Nishida 2003, Schmidt 2006), causing severe socioeconomic problems in the affected regions.

Evidence from a variety of sources (light and electron microscopy, behavioral tests, and molecular phylogenetics) indicated that LCD symptoms were associ- ated with the presence of a dematiaceous fungus (Boeger et al. 2005). Since then, further studies involving artificial infection experiments (Orélis-Ribeiro et al. 2011), as well as histopathological study of infected crabs (Boeger et al. 2007), sustain that LCD is associated with Exophiala cancerae de Hoog et al.. Although still unknown to science, the species was isolated earlier from other substrates (de Hoog et al. in press).

In the present study, we sequenced internal transcribed spacer (ITS) of the rDNA region of this black yeast species and developed specific markers that can be used in the diagnosis of sick individuals, in the molecular identification of cultured isolates, and in the prospecting of environmental samples.

Crabs with symptoms of LCD were obtained during outbreaks that occurred in the state of Sergipe in 2004 and 2005. The extraction of fungal DNA from the host tissues followed the protocol of Boeger et al. (2005), 
with the following modification: instead of submitting the yeast-like cells to cellular disruption by ultrasound, they were homogenized using a mortar and pestle in liquid nitrogen. The ITS of the rDNA was amplified using the primers ITS1F (5'-CTT GGT CAT TTA GAG GAA GTA A-3') and ITS4 (5'-TCC TCC GCT TAT TGA TAT GC-3') (White et al. 1990) in $25 \mu$ reactions with the following final concentrations: $3 \mathrm{mM}$ of $\mathrm{MgCl}_{2}$, $0.4 \mathrm{mM}$ of dNTPs, $1 \times$ reaction buffer, $2.5 \mathrm{U}$ of Taq polymerase (Biotools), $2 \mu \mathrm{M}$ of each primer, and 50 to $75 \mathrm{ng}$ of template DNA using the following program: 4 min at $95^{\circ} \mathrm{C}$, followed by 30 cycles of $1 \mathrm{~min}$ at $94^{\circ} \mathrm{C}, 2 \mathrm{~min}$ at $58^{\circ} \mathrm{C}, 1 \mathrm{~min}$ at $72^{\circ} \mathrm{C}$, and a final extension of $1 \mathrm{~min}$ at $72^{\circ} \mathrm{C}$. PCR products were electrophoresed on $1.5 \%$ agarose gels and stained with ethidium bromide for band visualization. Positive reactions were purified using the Minelute ${ }^{\circledR}$ (Qiagen) kit, and cycle sequencing was carried out using the following final concentrations: $0.16 \mu \mathrm{M}$ of primer, $1 \times$ reaction buffer, $0.5 \mu \mathrm{l}$ of BigDye v.3, and $40 \mathrm{ng}$ of template DNA. Thermocycling conditions included an initial denaturation of $1 \mathrm{~min}$ at $96^{\circ} \mathrm{C}$, followed by 35 cycles of $10 \mathrm{~s}$ at $96^{\circ} \mathrm{C}, 5 \mathrm{~s}$ at $50^{\circ} \mathrm{C}$, and $4 \mathrm{~min}$ at $60^{\circ} \mathrm{C}$. Products were purified using G-50 Sephadex, and both strands were sequenced on an ABI 3130 Automatic Sequencer. A representative sequence was deposited in GenBank under accession number HQ659023, and reference material has been submitted to the Centraalbureau voor Schimmelcultures, The Netherlands (CBS120420).

The obtained sequences were compared to those of several other species of black yeast and fungi to locate regions of maximum dissimilarity (particularly transversions and indels), which were used to design specific primers (Fig. 1). Several primer pairs were tested using both sensitivity and specificity tests. Sensitivity tests were carried out by using increasingly smaller amounts of template DNA (from 5 to $0.005 \mathrm{ng}$ ) to determine the extent of 'detectability' of the method. Specificity tests were conducted by testing the designed primers against samples of several other fungus species, including Ramichloridium atrovirens (CBS685.76), $R$. atrovirens (CBS677.76), Ramichloridium sp. (CBS102238), Fonsecaea pedrosoi (CBS253.49), Cladophialophora immunda (CBS102237), C. saturnica (CBS118724), Exophiala spinifera (HC-EML), and E. jeanselmei (HC-EJ4) (CBS and HC correspond to reference strains from the Centraalbureau voor Schimmelcultures, The Netherlands, and the Hospital de Clínicas of the Universidade Federal do Paraná, Brazil). The reaction with the specific primers that showed the best performance included the primers LCDF5 (5'-CCC TCT GGC CCG CGC TCG TCG ACA GC-3') and LCDR3 (5'-GAG AAA GAT TCT CCC TGA GGG GAG GCA G-3') in $25 \mu \mathrm{l}$ reactions with the following final concentrations: $3 \mathrm{mM}$ of $\mathrm{MgCl}_{2}, 0.4 \mathrm{mM}$ of dNTPs, $1 \times$ reaction buffer, $2.5 \mathrm{U}$ of Platinum Taq polymerase (Invitrogen), $2 \mu \mathrm{M}$ of each primer, and varying amounts of template DNA (see above). The following thermocycling conditions were used: initial denaturation for $5 \mathrm{~min}$ at $95^{\circ} \mathrm{C}$, followed by 25 cycles of $40 \mathrm{~s}$ at $94^{\circ} \mathrm{C}, 30 \mathrm{~s}$ at $70.5^{\circ} \mathrm{C}, 30 \mathrm{~s}$ at $72^{\circ} \mathrm{C}$, and a final extension of $2 \mathrm{~min}$ at $72^{\circ} \mathrm{C}$. Electrophoresis and band visualization were carried out as indicated above.

The results from sensitivity tests are presented in Fig. 2, showing that the specific primers provided positive results reliably with as little as $0.05 \mathrm{ng}$ of fungal DNA, although a faint discernible band was also present in the reaction with $0.005 \mathrm{ng}$. No unspecific band was visible when only DNA from Ucides cordatus was present in the reaction. Moreover, none of the tests using $2 \mathrm{ng} \mathrm{hl}^{-1}$ of other fungal species provided falsepositive results (Fig. 3).

\section{LCDF5}

Target sequence - Exophiala sp. AB190392.1 Cadophora fastigiata AF050272.1 Exophiala pisciphila FM172777.1 Calluna vulgaris EU041819.1 Veronaea compacta

I.

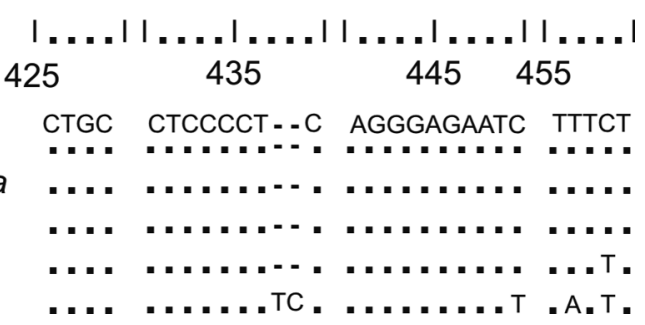

Fig. 1. Multiple alignment of the sequenced internal transcribed spacer fragment of Exophiala cancerae (CBS120420) and closely related species indicating the location of the new specific primers LCDF5 and LCDR3. GenBank accession numbers are indicated next to species names 


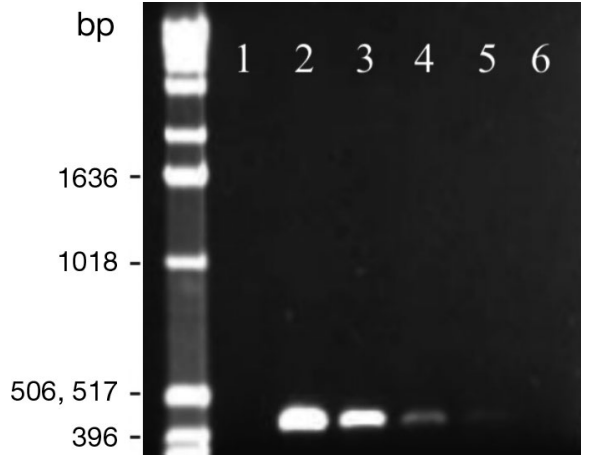

Fig. 2. Sensitivity tests of the specific primers for the detection of the Exophiala-like black yeast associated with lethargic crab disease. Template DNA for the PCR in each lane: Lane 1, genomic DNA of Ucides cordatus; Lanes 2-5, respectively, 5, $0.5,0.05$, and $0.005 \mathrm{ng}$ of fungal DNA; Lane 6, negative control

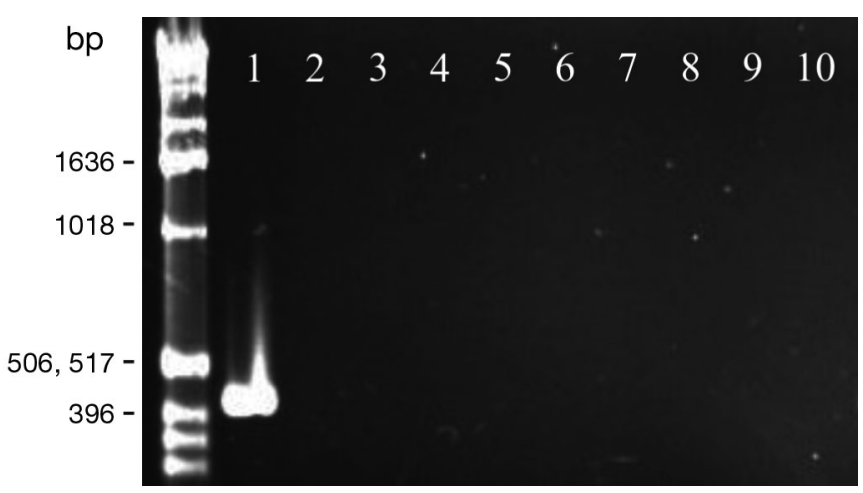

Fig. 3. Specificity tests of the specific primers for the detection of the Exophiala-like black yeast associated with lethargic crab disease. Template DNA for the PCR in each lane: Lane 1, E. cancerae (CBS120420); Lane 2, Ramichloridium atrovirens (CBS685.76); Lane 3, R. atrovirens (CBS677.76); Lane 4, Ramichloridium sp. (CBS102238); Lane 5, Fonsecaea pedrosoi (CBS253.49); Lane 6, Cladophialophora immunda (CBS102237); Lane 7, C. saturnica (CBS118724); Lane 8, E. spinifera (HC-EML); Lane 9, E. jeanselmei (HC-EJ4); Lane 10, negative control

The protocol using these specific primers was also applied in laboratory experiments (Orélis-Ribeiro et al. 2011), in the diagnosis of diseased crabs, and on Exophiala cancerae isolates obtained from outbreaks in other states (Bahia and Espírito Santo), confirming the adequacy of the method. Moreover, this method was used in an environmental screening of isolates from mangroves in the state of Bahia (R. S. Guerra unpubl. results). The results of this screening study corroborate the usefulness of the ITS region in the development of species-specific primers, as has been shown in a wide variety of fungal groups (e.g. LoBuglio \& Taylor 1995, Amicucci et al. 1998, Redecker 2000).

The unpredictable nature of LCD outbreaks, in both space and time, is an important limitation to the study of this disease. The specific primers provided in the present study represent an important tool for rapidly surveying a large number of crab individuals, as well as environmental samples. Such knowledge is instrumental in understanding the epidemiological dynamics of LCD and will allow management efforts of this important fishery to be optimized.

Acknowledgements. This study was funded by the Companhia de Desenvolvimento Industrial e de Recursos Minerais de Sergipe (CODISE). The Conselho Nacional de Desenvolvimento Científico e Tecnológico provided fellowships to W.A.B. and R.O.R.

\section{LITERATURE CITED}

Amicucci A, Zambonelli A, Giomaro G, Potenza L, Stocchi V (1998) Identification of ectomycorrhizal fungi of the genus Tuber by species-specific ITS primers. Mol Ecol 7:273-277

Boeger WA, Pie MR, Ostrensky A, Patella L (2005) Lethargic crab disease: multidisciplinary evidence supports a mycotic etiology. Mem Inst Oswaldo Cruz 100:161-167

Boeger WA, Pie MR, Vicente V, Ostrensky A, Hungria D, Castilho GG (2007) Histopathology of the mangrove land crab Ucides cordatus (Ocypodidae) affected by lethargic crab disease. Dis Aquat Org 78:73-81

de Hoog GS, Vicente VA, Najafzadeh MJ, Harrak MJ, Seyedmousavi S (in press) Waterborne Exophiala species causing disease in cold-blooded animals. Stud Mycol

LoBuglio KF, Taylor JW (1995) Phylogeny and PCR identification of the human pathogenic fungus Penicillium marneffei. J Clin Microbiol 33:85-89

Nóbrega RR, Nishida AK (2003) Aspectos socioeconômicos e percepção ambiental dos catadores de caranguejo-uçá, Ucides cordatus (L. 1763) (Decapoda, Brachyura) do estuário do rio Mamanguape, Nordeste do Brasil. Interciencia 28:36-43

Orélis-Ribeiro R, Boeger WA, Vicente VA, Chammas $M$, Ostrensky A (2011) Fulfilling Koch's postulates confirms the mycotic origin of lethargic crab disease. Antonie Leeuwenhoek doi:10.1007/s10482-010-9531-4

Redecker D (2000) Specific primers to identify arbuscular mycorrhizal fungi within colonized roots. Mycorrhiza 10: $73-80$

Schmidt A (2006) Estudo da dinâmica populacional do caranguejo-uçá, Ucides cordatus cordatus (Linnaeus, 1763) (Crustacea-Decapoda-Brachyura), e dos efeitos de uma mortalidade em massa desta espécie em manguezais do Sul da Bahia. MSc thesis, Instituto Oceanográfico, Universidade de São Paulo

White TJ, Bruns T, Lee S, Taylor J (1990) Amplification and direct sequencing of fungal ribosomal RNA genes for phylogenetics. In: Innis MA, Gelfand DH, Sninsky JJ, White TJ (ed) PCR protocols: a guide to methods and applications. Academic Press, San Diego, CA, p 315-322 